Loyola University of Chicago

Paul K. Moser

\title{
SCIENTIFIC RATIONALITY AND PROGRESS: A PARADOX IN LAUDAN'S ACCOUNT
}

Imre Lakatos once remarked that „the central problem in philosophy of science is the problem of normative appraisal of scientific theories" " . Although Lakatos may have exaggerated the significance of this problem, it is crucial for any philosophy of science to give an account of the rational appraisal of scientific theories. Thus, a significant question for any philosophy of sciences is: How do scientists, and the rest of us for that matter, determine that one scientific theory is rationally preferable to another? Larry Laudan, in Progress and Its Problems (Berkeley: University of California Press, 1977), has developed a provocative answer to this question. In this paper, I shall outline Laudan's answer, and then show that Laudan's account of scientific rationality is fundamentally inconsistent.

\section{LAUDAN'S ACCOUNT}

Laudan's problem-oriented theory of science depicts scientific theories as answers to scientific problems. Scientific problems, on his theory, are of two very different kinds: empirical and conceptual. Empirical problems are those problems that scientists treat as problems about the world itself, rather than as problems merely about theories. One standard empirical problem is the familiar question of how and why heavy bodies fall toward the earth with regularity. The empirical problems of the natural sciences are thus those first order problems that concern

1 I. Lakatos and E. Zahar, Why Did Copernicus Programme Supersede Ptolemy's?, [in:] I. Lakatos, The Methodology of Scientific Research Programmes, vol. 1: Philosophical Papers, eds. J. Worrall and G. Currie (Cambridge: Cambridge University Press, 1978), p. 168. 
the objects constituting the domain of the natural sciences. But empirical problems are not identical with facts, as such problems need not describe actual states of affairs. They need only be thought by scientists to describe actual states of affairs (pp. 1617) ${ }^{2}$.

Empirical problems come in three main forms: solved, unsolved, and anomalous. Unsolved empirical problems are those empirical problems that have not been solved by any theory, and solved empirical problems are those empirical problems that have been solved by some theory or other. Anomalous empirical problems for a theory are those empirical problems which that theory has not solved, but which some rival theory has solved.

Laudan's view of anomalies differs from familiar views in circulation. An anomaly, on his view, is an empirical situation that raises doubts about the empirical adequacy of a theory, but it need not compel or require the rejection of that theory (p. 27). Further, an anomaly need not be inconsistent with the theory about which it raises doubts. It need only be incapable of being solved by that theory. An empirical problem is an anomaly, on Laudan's view, only if it has been solved by some rival or other of the theory for which it is anomalous. Thus, Laudan's use of 'anomaly' contrasts with familiar use.

Laudan recognizes conceptual problems in addition to empirical problems for theories. A conceptual problem is a nonempirical problem. Specifically, it is a characteristic of a theory, and does not exist independently of a theory (p. 48). A conceptual problem is, in effect, a higher order question about the well-foundedness of a theory.

A conceptual problem can take either of two forms: internal or external. A theory has an internal conceptual problem if it is either internally inconsistent or excessively vague. And a theory has an external conceptual problem if it is inconsistent with some other theory that is well-founded. Logical inconsistency, however, is not the only kind of conflict that provides an external conceptual problem. A theory, $T$, may exhibit an external conceptual problem if $T$ is implausible in conjunction with some other theory, T', that is widely believed to be rationally well- founded, even though $T$ and $T^{\prime}$ are logically consistent. Or, alternatively, $T$ may exhibit an external conceptual problem if $T$ is merely compatible with $T$ ' when $T$, in light of certain other well-founded beliefs, ought to reinforce T'. Laudan claims that such conceptual problems have been largely ignored by historianis and philosophers of science because such problems do not fit well with empiricist theories of scientific rationality.

On Laudan's view, conceptual problems play a central role in the rational appraisal of scientific theories.

Laudan holde that scientific problems can differ in rational significance as well as in general form. Thus, on his view, some solved problems are rationally more significant than others, and some anomalies are rationally more problematic than others.

\footnotetext{
${ }^{2}$ All page references in parentheses refer to Laudan's Progress and Its Problems.
} 
Laudan has provided some general guidelines for the rational weighting of scientific problems on a scale of relative importance (pp. 32-40). Regarding solved problems, four criteria of a rationally significant problem are noteworthy. (1) If a problem has been solved by a particular theory, then that problem qualifies as a rationally significant problem for any rival theory. (2) If a problem has proved to be anomalous for any theory, then any theory that solves that problem has solved a rationally significant problem. (3) If a problem concerns the primary or basic natural processes to which other processes must be reduced, then that problem is rationally significant. (4) If one problem, $P$, is more general than another problem, $\mathrm{P}$ ' (in the sense that any solution to $P$ entails a solution to $\mathrm{P}^{\prime}$ too), then $\mathrm{P}$ is rationally more significant than P'.

There are, on Laudan's account, still other factors that determine the rational weight of an anomalous problem. One additional factor is the degree of discrepancy between an experimental result and a theoretical prediction. Another factor is an anomaly's age, the period of its demonstrated resistance to solution by a theory. The older an anomaly is for a theory, the more significant it is for that theory. We could list other relevant factors, but the foregoing considerations should be adequate to give some sense to the notion of one problem's being rationally more significant than another problem.

Laudan's account requires that we introduce one more important distinction: a distinction between two different sorts of propositional networks within the class of scientific theories. The term theory may refer, on the one hand, to a very specific set of related doctrines, such as Einstein's theory of the photoelectric effect. On the other hand, theory may refer to much more general sets of doctrines or assumptions, such as the theory of evolution. In the latter case, the term refers not to an individual theory, but to a family of theories. Laudan calls such a family of theories a research tradition. And he holds that such global theories are the primary tool for appraising scientific progress (p. 72).

A research tradition is basically a complex of ontological and methodological assumptions. It indicates in a general way both the basic entities of nature and the appropriate methods for investigating those entities. In Laudan's words, , , a research tradition is thus a set of ontological and methodological do's and don'ts" (p. 80) ${ }^{3}$. On Laudan's account, a research tradition, in contrast with a theory, is not directly testable. It does, however, provide the scientist with the requisite tools for solving empirical and conceptual problems. A research tradition, according to Laudan, can be considered successful if its component theories adequately solve the pressing empirical and conceptual problems that confront those theories.

Laudan has set forth some general guidelines for the rational evaluation of a research tradition (pp. 106-114). He holds that such evaluation is always a

${ }^{3}$ Laudan is rather unclear on identity conditions for a research tradition. On the one hand, he holds that a research tradition can undergo mutually contradictory formulations (p. 79), but, on the other hand, he claims that the scientist who breaks with the ontology of a research tradition divorces himself from that research tradition (p. 80). One ist left wondering, after all, whether logical consistency is a necessary condition of a research tradition. 
comparative matter. One mode of evaluation is synchronic; another is diachronic or developmental. Synchronic evaluation concerns the momentary adequacy of a research tradition. Diachronic evaluation concerns the progressiveness of a research tradition. We evaluate the momentary adequacy of a research tradition by determining how effective the latest theories within that tradition are at solving problems. The progressiveness of a research tradition, in contrast, is determined by consideration of whether that research tradition has increased or decreased the problem-solving effectiveness of its component theories throughout a certain period of time. If a research tradition increases the problem-solving effectiveness of its component theories, and thereby increases it momentary adequacy, then it is progressive.

Laudan distinguishes the rate of progress of a research tradition from the general progress of a research tradition. The rate of progress is determined by the changes in the momentary adequacy of the research tradition during a certain time span. And the general progress is a function of the difference between (a) the adequacy of those theories constituting the oldest versions of a research tradition and (b) the adequacy of those theories constituting the newest versions of that tradition (p. 107). Clearly, the general progress and the rate of progress of a research tradition can vary, as a research tradition can exhibit a high rate of progress and a low degree of general progress, and conversely.

Thus, Laudan distinguishes between two modes of rational appraisal: acceptance and pursuit. These are two different contexts within which research traditions, as well as theories, are rationally evaluated. The context of pursuit, on Laudan's account, involves criteria of rational appraisal that are significantly different from such criteria within the context of acceptance. Specifically, Laudan holds that ,it is always rational to pursue any research tradition which has a higher rate of progress than its rivals" (p. 111). Thus, on his view, a scientist may rationally pursue a research tradition even if there are insufficient grounds for the rational acceptance of that research tradition. Such pursuit might be motivated, for instance, by a desire to incorporate some elements of a rationally unacceptable research tradition into a rationally acceptable research tradition.

Laudan's account of rational appraisal requires a definition of a theory's problemsolving effectiveness. Problem-solving effectiveness, on his acount, is determined by assessing the number and importance of the empirical problems that a theory solves, and by subtracting therefrom the number and importance of the anomalous problems and conceptual problems confronting that theory (p. 68). A theory may be regarded as having solved an empirical problem, on Laudan's view, so long as that theory entails at least an approximate statement of that problem (pp. 22-25). So, Laudan holds that whether a theory is true is irrelevant to whether that theory solves an empirical problem. In addition, a theory need not be well-confirmed in order to be a problem- solution. A problem-solving theory need only play an important role in an inference schema whose conclusion is at least an approximate statement of the solved problem in question. But Laudan stresses that a theory can cease to be an adequate problem-solution at some time, on the ground that the standards for a rationally 
adequate problem-solution change through time (pp. 25-26).

A problem-solution, as well as a research tradition, may be either progressive or non-progressive. One problem-solution is progressive in comparison with another if and only if the former is a more effective problem-solver, i.e., a theory with more problem-solving effectiveness than the latter (pp. 68 f., 107 f.). Further, a theory or research tradition may be considered to be most progressive if and only if it has more problem-solving effectiveness than any rival.

Laudan's main innovation is to defined scientific rationality in terms of progressiveness, which in turn is defined in terms of problem-solving effectiveness. A problem-solution is rationally adequate, on his view, if and only if that solution increases progressiveness, i.e., if and only if it increases the problem-solving effectiveness of our accepted theories. Conversely, a problem-solution that decreases the problem-solving effectiveness of our accepted theories is rationally inadequate. Scientific rationality, on Laudan's view, is thus parasitic upon progressiveness (p. 125).

\section{ŚOME PROBLEMS}

Laudan's problem-oriented model of scientific rationality has two seriously troublesome implications. First, on this model, there is no rational way to preclude ad hoc modifications of a scientific theory, so long as those modifications increase problem-solving effectiveness. For as long as ad hoc modifications increase problem-solving effectiveness, they will be progressive and thus rational. In short, Laudan's account implies that ad hoc problem-solutions are rationally virtuous (p. 115). On this view, accordingly, the scientist may formulate and rationally accept any number of hypotheses with very narrow, makeshift application, so long as they increase problem-solving effectiveness. But this position ignores the prominence of the principle of theoretical simplicity in modern science ${ }^{4}$. In fact, this position sacrifices theoretical simplicity for the sake of ad hoc problem-solving effectiveness. Laudan fails to show that such a sacrifice is in fact rationally appropriate. And he appears not to have the history of modern science on his side.

The second troublesome implication involves an inconsistency in Laudan's notion of a rationally adequate problem-solution. Laudan's main innovative thesis, as I noted, is that scientific rationality is parasitic upon progressiveness. A problemsolution, on his view, is rationally adequate if and only if it is progressive. Progressiveness, in turn, is defined by Laudan in terms of a problem-solution that increases the problem-solving effectiveness of our accepted theories. But what are the criteria for what counts as a rationally adequate problem-solution to a particular scientific problem? This question leads to trouble for Laudan's account.

Laudan denies that there is any simple answer to the foregoing question, on the ground that criteria for a rationally adequate problem- solution evolve through time (pp. 25 f.). Many problem-solutions regarded as rationally adequate by earlier

\footnotetext{
${ }^{4}$ For some evidence that theoretical simplicity is a scientific standard that precludes $a d$ hoc hypotheses, see Paul Thagard, The Best Explanation: Criterial for Theory Choice, The Journal of Philosophy, 75 (1978), 86-89.
} 
scientists (e.g., Aristotle's solution to the problem of the fall of a body) are now regarded as completely adequate. Thus, Laudan holds that the history of science is unintelligible on the view that the standards of rational adequacy remain static throughout history (pp. $128 \mathrm{f}$.).

We can grant, if only for the sake of argument, that what scientists believe to be correct standards of rationality change over time. And we might even grant that what actually are correct standards of rationality evolve throughout history. But even so, it does not follow that rationa- lity is parasitic upon progressiveness. On the contrary, we can plausibly argue that the notion of rationality is basic to, or presupposed by, Laudan's notion of progressiveness; that the notion of progressiveness is parasitic upon the notion of rationality. If progressiveness is defined, following Laudan, in terms of (adequate) problem-solutions that increase problem-solving effectiveness, and if the notion of an adequate problem-solution depends, as Laudan holds, on certain widely accepted standards of rational adequacy, then the notion of progressivenes itself depends on certain standards of rational adequacy. In short, the notion of progressiveness is parasitic upon the notion of rationality.

Rational scientific inquiry rests on the question of which theories, among the many explanatory competitors, are rationally adequate problem-solutions. Certain standards of rational adequacy must be employed to discriminate rationally between rival problem-solutions. These standards are essential to the notion of rational scientific appraisal. Many modem scientists appeal to such standards (or values) as accuracy, simplicity, broad scope, fruitfulness, and consistency to determine which problem-solutions are rationally adequate and which are not ${ }^{5}$. Without some such standards, it is doubtful that the rational appraisal of scientific theories would be effective or even unintelligible. At least, Laudan has given us no reason to remove this doubt.

In fact, Laudan appears at times to concede my point regarding the primacy of the notion of a rationally adequate problem-solution. For he affirms this:

(1) The prevailing standards of rational adequacy are needed to determine which of the rival theories are adequate problem-solutions and which are not (pp. 25f.).

A debilitating paradox for Laudan's account arises when he also affirms this:

(2) The notion of rationality is parasitic upon the notion of progressiveness, i. e., the notion of problem-solutions that increase the problem-solving effectiveness of our accepted theories (p. 125).

How can Laudan consistently endorse both (1) and (2)?

I have suggested that the notion of rational adequacy is required in advance to make rational appraisals of the relative rational merits and demerits of scientific theories (e.g., to determine rationally which theories are adequate problemsolutions). Laudan's position (1) implies as much. But given (1), the notion of

${ }^{5}$ For discussion of the role of such standards in scientific theory-choice, see Thomas Kuhn, Objectivity, Value Judgement, and Theory Choice, [in:] Th. Kuhn, The Essential Tension (Chicago: University of Chicago Press, 1977), p. 320-329. 
rational adequacy cannot be introduced derivatively in terms of position (2), i.e., as being parasitic upon the notion of increased problem-solving effectiveness, or progressiveness. If the notion of rational adequacy is introduced derivatively, as in position (2), then this notion cannot consistently be invoked in advance to determine which theories are rationally adequate problem-solutions.

In brief, the notion of rational adequacy is either basic to the notion of progressiveness or derived from it - one or the other, but not both. Laudan's account of scientific rationality implies that the notion of rational adequacy is both basic to and derived from the notion of progressiveness. Thus, his account is fundamentally inconsistent, or at least conceptually circular.

One might propose that Laudan's way out of inconsistency is to deny (2) and to affirm (1). For he cannot have his notion of progressiveness without (1), simply because the notion of an adequate problem- solution presupposes standards of rational adequacy, standards essential to rational appraisal. But this proposal robs Laudan's account of its main innovation: the attempt to make rationality parasitic upon progressiveness. The denial of (2) leaves Laudan without a distinctive account of rationality. On the other hand, it is doubtful that Laudan can plausibly deny (1), since he then loses a relevant notion of an adequate problem-solution.

\section{CONCLUSION}

I conclude, then, that Laudan's model of scientific rationality, although provocative, is paradoxical and hence in need of substantial revision. Perhaps problem-solving is somehow relevant to scientific rationality, but we still need an account of how it can be definitive of such rationality. 